\title{
Uso de células imobilizadas em gel de PVA: uma nova estratégia para produção biotecnológica de Xilitol a partir de bagaço de cana-de-açúcar
}

\author{
Use of PVA-gel immobilized cells: \\ a new strategy for biotechnological production of Xylitol \\ from sugarcane bagasse hidrolysate
}

\author{
Mário Antônio Alves da Cunha ${ }^{1 *}$; Silvio Silvério da Silva ${ }^{2}$; \\ Walter de Carvalho ${ }^{3}$; Júlio César dos Santos ${ }^{3}$
}

\section{Resumo}

O bagaço de cana-de-açúcar é um dos resíduos mais abundantes no Brasil devido ao grande número de indústrias sucroalcooleiras. Esta biomassa contém elevado teor de carboidratos, podendo ser utilizada na produção de compostos de interesse econômico como o xilitol. O xilitol é um poliol de cinco carbonos que apresenta poder adoçante semelhante ao da sacarose e propriedades anti-cariogênicas, tendo elevado potencial de uso nas indústrias alimentícias e farmacêuticas. Diversos estudos buscando o desenvolvimento de processos de produção de xilitol por via biotecnológica têm sido realizados, entretanto pouco tem sido escrito sobre a utilização de células imobilizadas no bioprocesso. A presente revisão tem como objetivo apresentar uma possibilidade de produção de xilitol a partir de hidrolisado hemicelulósico de bagaço de canade-açúcar, em sistema com células imobilizadas em gel de álcool polivinílico.

Palavras-chave: Bagaço de cana-de-açúcar, xilitol, processos biotecnológicos, resíduos agro-industriais, PVA, álcool polivinílico

\begin{abstract}
Sugarcane bagasse is one of the most abundant residues in Brazil due to the large number of sugaralcohol industries. This biomass contains a high concentration of carbohydrates, which can be converted into products of high economic value, such as xylitol. Xylitol, a polyol with anticariogenic properties, is similar in sweetening power to sucrose, and has high potential for use in the food and pharmaceutical industries. Several studies have been carried out to produce xylitol by biotechnological processes. However, there is little information on the use of immobilized cells in these bioprocesses. The objective of this review was to present a new possibility to produce xylitol by biotechnological processes, using sugarcane bagasse hydrolysate and immobilized cells in PVA-gel.
\end{abstract}

Key words: Sugarcane bagasse, xylitol, biotechnological processes, agro industrial residues, PVA, poly (vinyl alcohol)

\footnotetext{
'Doutorando em Biotecnologia Industrial - Faculdade de Engenharia Química de Lorena / FAENQUIL. e-mail mariocunha@debiq.faenquil.br.

2 Professor/Pesquisador - Departamento de Biotecnologia / FAENQUIL.

3 Doutor em Biotecnologia Industrial.

Autor para Correspondência.
} 


\section{Bagaço de cana-de-açúcar: uma biomassa abundante e renovável no Brasil}

Os lignocelulósicos são os materiais orgânicos mais abundantes da biosfera, representando aproximadamente $50 \%$ da biomassa vegetal (GOLDSTEIN, 1991) e podem ser usados como matéria-prima em processos industriais para a produção de alimentos, combustíveis, insumos químicos, enzimas e bens de consumo diversos (KADAM; FORREST, JACOBSON, 2000; KRISHNA; REDDY; CHOWDARY, 2001; LATIF; RAJOCA, 2001).

O Brasil, com sua grande extensão territorial apresenta alto potencial de exploração de recursos renováveis para a geração de diversos insumos. Um resíduo abundante no país e proveniente de material renovável é o bagaço de cana-de-açúcar, pois o Brasil é o maior produtor de cana-de-açúcar do mundo com uma produção estimada de aproximadamente 390 milhões de toneladas no ano de 2004, segundo dados do Ministério da Agricultura (BRASIL. Ministério da Agricultura, 2004).

Uma indústria sucroalcooleira produz cerca de 280 kg de bagaço por tonelada de cana moída (MOLINA et al., 1995) o que correspondeu a uma produção de bagaço de aproximadamente 100 milhões de toneladas no ano de 2004. Grande parte deste resíduo, também considerado por muitos como subproduto, é utilizada pela própria usina como fonte de energia.

Embora o bagaço possa ser utilizado para geração de energia ou como suplemento em ração animal, ainda há um grande excedente que pode ser utilizado para produção de diversos bens à sociedade.

Algumas alternativas para sua utilização como matéria prima são a produção de etanol, hidroximetilfurfural, papel e celulose, revestimentos acústicos, madeira prensada, forragem para agricultura, álcool, alcalóides, enzimas e xilitol (CARVALHO et al., 2002; LACÔRTE; BURGE; LACÔRTE, 1986; PANDEY, et al., 2000; SILVA; MARTINEZ; FELIPE, 2000; SILVA et al., 2001; SILVA; CARVALHO, 2002; SILVA et al., 2002).
A biotecnologia tem sido bastante explorada nos últimos anos para a obtenção de inúmeros produtos de interesse econômico e social. Os processos biotecnológicos têm se mostrado promissores e com inúmeras vantagens em relação aos processos convencionais. Segundo Du Toid, Olivier e Van Biljon (1984), o aproveitamento do bagaço de cana-deaçúcar como fonte de substratos para a utilização em processos biotecnológicos é uma alternativa atrativa e promissora, considerando-se o elevado teor de carboidratos presentes nesta biomassa. Neste contexto, a xilose presente na fração hemicelulósica pode ser utilizada na produção de xilitol, uma vez que esta pentose pode perfazer até $80 \%$ dos carboidratos presentes na fração hemicelulósica do bagaço de cana (KUHAD; SINGH, 1994).

\section{Xilitol: possibilidade de utilização em diversas áreas}

O xilitol apresenta poder adoçante equivalente ao da sacarose (BÄR, 1986) e possui propriedades anticariogênicas, uma vez que não é fermentado pelos microrganismos da microflora bucal (PEPPER; OLINGER, 1998). Contribui para a saúde bucal de seis maneiras: reduzindo a incidência de cáries; estabilizando íons cálcio e fosfato na saliva e conseqüentemente remineralizando os dentes; estabilizando as cáries já formadas; reduzindo o crescimento de Streptococcus mutans e Lactobacillus spp. na saliva; estimulando a formação da saliva sem aumento da produção de ácidos na placa dentária; controlando o $\mathrm{pH}$ da placa e a capacidade tamponante da saliva, após o consumo de sacarose (KANDELMAN, 1997; MÄKINEN, 2000).

Seu uso é indicado para pessoas diabéticas, uma vez que seu metabolismo é independente de insulina (PEPPER; OLINGER, 1998; YLIKAHRI, 1979), sendo também indicado para pacientes portadores de deficiência da enzima glicose 6-fosfato desidrogenase (BÄR, 1986) e como adoçante dietético (PEPPER; OLINGER, 1988; BÄR, 1991).

Como substituto da sacarose em alimentos, o xilitol possui grandes vantagens em relação aos outros 
adoçantes convencionais, pois além de tornar o produto aceitável em termos de sabor e apresentar caráter anticariogênico, a incorporação de xilitol em alimentos torna estes produtos acessíveis para pacientes diabéticos e para aqueles que apresentam desordens no metabolismo de lipídeos (MÄKINEN, 1976; YLIKAHRI, 1979).

O xilitol não participa de reações de escurecimento do tipo Maillard devido à ausência de grupos aldeídicos e cetônicos na sua molécula, o que o torna apropriado para a utilização em alimentos processados em temperaturas elevadas (MANZ; VANNINEN; VOIROL, 1973), além de apresentar elevado calor de dissolução que confere sensação agradável de frescor, tornando-o apropriado ao revestimento de gomas de mascar (MÄKINEN, 1976). Ressalta-se ainda que, pelo fato deste adoçante apresentar poder de edulcoração semelhante ao da sacarose, a sua utilização pela indústria alimentícia na confecção de alimentos dietéticos em substituição ao açúcar é vantajosa quando comparada aos demais adoçantes, pois como a substituição ocorre na proporção de 1:1, o balanço de massa dos produtos não é afetado, proporcionando manutenção das propriedades sensoriais do produto final (EMODI, 1978). Outras aplicações deste poliálcool têm sido estudadas, como seu uso na prevenção de infecções bacterianas (UHARI; APIAINEN; KONTIOKARI, 2000), na prevenção da otite aguda (UHARI; KONTIOKARI; NIEMELA, 1998), na formulação de infusões pos-cirúrgicas para pacientes com dificuldades em metabolizar açúcares (MAKINEN, 2000) e na prevenção da osteoporose (MATTILA et al., 2002).

É uma substância atóxica, classificada pela Food and Drug Administration (FDA) como um aditivo do tipo GRAS (Generally Recognised as Safe) (CULBERT et al., 1986). No Brasil, de acordo com a Agência Nacional de Vigilância Sanitária (Anvisa) é classificado como um aditivo alimentar do tipo umectante, que pode ser empregado em balas, confeitos, gomas de mascar e produtos do gênero, na quantidade necessária para se obter o efeito desejado ( "quantum satis"), uma vez que não afeta a identidade e a genuidade dos alimentos (ANVISA, 2004a, 2004b).

\section{Processos de produção de Xilitol}

O xilitol ocorre naturalmente em certos frutos e vegetais. Entretanto, a extração a partir destas fontes é economicamente inviável devido às baixas concentrações (MEYRIAL, et al., 1991). Industrialmente é produzido pela redução catalítica de uma solução de xilose com elevado grau de pureza em presença do catalisador Níquel de Raney (HYVÖNEN; KOIVISTOINEN; VOIROL, 1982; MELAJA; HÄMÄLÄINEN, 1977). Este processo é de custo elevado, pois são empregadas altas temperaturas e pressões, além de serem necessárias extensivas etapas de purificação da xilose antes de sua hidrogenação a xilitol visando à eliminação de impurezas que possam interferir na catálise. Também são requeridas etapas de purificação após a redução da xilose para a remoção do catalisador, para que o xilitol possa ser empregado em produtos alimentícios e farmacêuticos (NOLLEAU, PREZIOSIBELLOY; NAVARRO, 1995; OJAMO; YLINEN; LINKO, 1988).

A existência de desvantagens no processo convencional de produção de xilitol, como a necessidade do uso de xilose com alto grau de pureza e o uso de elevadas temperaturas e pressões no processo, tem motivado os pesquisadores a buscarem vias alternativas para sua obtenção. Outra motivação é o alto nível de poluição e a necessidade de tratamento dos resíduos inerentes à rota química. Um dos processos mais atrativos é a via microbiológica (WINKELHAUSEN; KUSMANOVA, 1998), que apresenta vantagens como o uso de condições amenas de pressão e temperatura (SILVA et al., 1997), a possibilidade de utilização de xilose impura, uma vez que os microrganismos são capazes de converter xilose em xilitol diretamente a partir do hidrolisado hemicelulósico (ROSEIRO, et al., 1991) e o fato de que a via biológica não leva à formação 
de resíduos tóxicos que precisariam ser removidos nas etapas de purificação (OJAMO; YLINEN; LINKO, 1988).

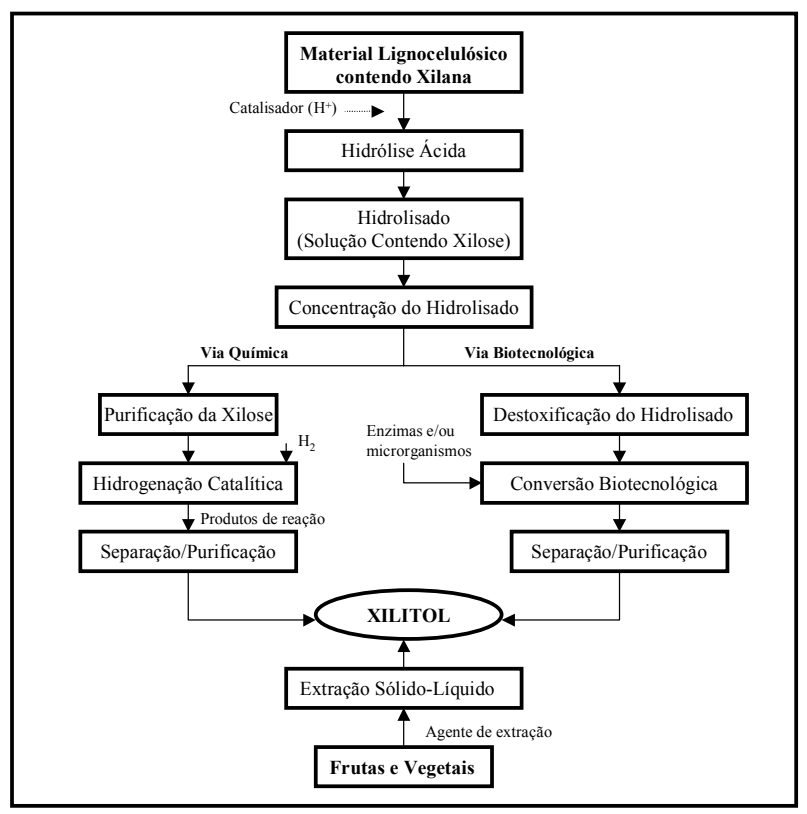

Figura 1 - Tecnologias disponíveis para obtenção de xilitol

A obtenção de xilitol por via biotecnológica é possível devido à capacidade de alguns microrganismos, especialmente leveduras, de sintetizarem a enzima xilose redutase, que catalisa a redução de xilose a xilitol como primeiro passo do metabolismo desta pentose (BARNETT, 1976; JEFFRIES, 1983). Em geral, entre os microrganismos, as leveduras são consideradas as melhores produtoras de xilitol, especialmente aquelas que pertencem ao gênero Candida, permitindo a obtenção de maiores taxas de conversão (WINKELHAUSEN; KUSMANOVA, 1998).

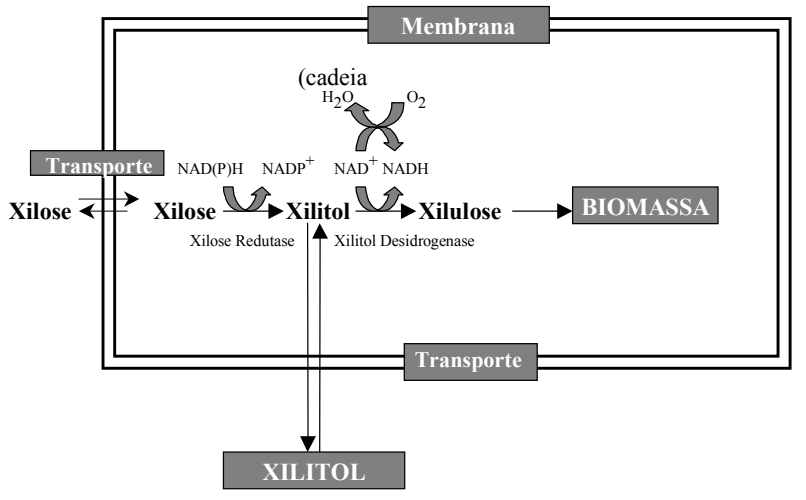

Figura 2 - Esquema simplificado do metabolismo de xilose em leveduras

\section{Imobilização celular na produção de Xilitol}

Existem quatro princípios básicos para a imobilização de biocatalisadores, a ligação a superfícies, o aprisionamento em matrizes porosas, a contenção por membranas e a auto-agregação (GERBSCH; BUCHHOLZ, 1995).

O método de imobilização por meio de ligação a superfícies pode ser feito por meio de interações iônicas ou adsortivas, ou através de ligações covalentes entre grupos reativos do suporte e do biocatalisador. A ligação por meio de adsorção e/ou interações iônicas é um método simples e barato, sendo a principal desvantagem a vulnerabilidade de perda dos biocatalisadores imobilizados para o meio reacional. Por outro lado a imobilização por meio de ligações covalentes resulta em uma interação biocatalizador-suporte mais forte, sendo a principal desvantagem o risco de danos à membrana celular, no caso de imobilização de células (GROBOILLOT et al., 1994). Suportes porosos têm sido geralmente utilizados para aumentar a massa de biocatalizadores imobilizados, permitindo também a ligação do biocatalizador à estrutura superficial interna. 
A imobilização por meio de aprisionamento em matrizes porosas envolve a síntese in situ da matriz porosa em torno dos biocatalizadores a serem imobilizados. Este método tem sido extensivamente estudado para a imobilização de células viáveis, devido à possibilidade de uso de polímeros hidrofílicos biocompatíveis como suportes de imobilização (GROBOILLOT et al., 1994). Além disso, as células imobilizadas em uma matriz hidrofílica podem ser protegidas de condições não amenas de $\mathrm{pH}$, temperatura, solventes orgânicos e/ou compostos inibidores presentes no meio de fermentação (PARK; CHANG, 2000). Como a matriz de aprisionamento geralmente resulta em limitações de transferência de massa, a imobilização na forma de esferas é geralmente preferida devido à elevada área superficial (GROBOILLOT et al., 1994). Como principais desvantagens são citados o pequeno volume disponível para a contenção das células imobilizadas, a perda de células para o meio de fermentação, que limitam a quantidade de células imobilizadas nas esferas e a instabilidade dos suportes normalmente utilizados, que limita a utilização dos agregados por longos períodos (PARK; CHANG, 2000).

O método de imobilização por meio de contenção em membranas envolve a utilização de membranas pré-formadas (reatores do tipo hollow fiber) ou a formação in situ da membrana em torno das células a serem imobilizadas (KAREL et al., 1985). Este método, também conhecido como encapsu- lamento, tem sido utilizado como uma tecnologia alternativa ao aprisionamento em matrizes porosas, uma vez que oferece vantagens como maior capacidade de contenção de células e prevenção da perda de células para o meio de fermentação. Devido à ausência de núcleo gelificado, as limitações à transferência de massa também são reduzidas (PARK; CHANG, 2000). Uma aplicação promissora deste princípio de imobilização é a contenção de biocatalisadores em micro esferas do tipo hollow fiber, formadas através de interações iônicas entre sulfato de celulose e cloreto de poli-dimetil-dialil-amônio (GERBSCH; BUCHHOLZ, 1995).
O método de imobilização por meio de autoagregação envolve a agregação ou a floculação das células de maneira natural ou artificialmente induzida. Desta forma, os biocatalisadores são ligados entre si sem a necessidade de uso de um suporte de imobilização. A floculação natural é uma propriedade de relativamente poucas células. Além disso, agregados celulares naturais são geralmente instáveis e sensíveis a tensões de cisalhamento, sendo necessária a adição de agentes químicos que formam ligações cruzadas entre as células, como glutaraldeído, durante a imobilização (GROBOILLOT et al., 1994).

Tem sido observado crescente aumento no desenvolvimento de bioprocessos empregando células imobilizadas, bem como grande número de publicações de trabalhos onde esta técnica é explorada (FERNÁNDEZ DEGIORGI et al., 2002; GIULIANO, et al., 2003; PASCO et al., 2004) o que mostra a importância e o interesse nesta tecnologia. Entretanto, especificamente na produção de xilitol, o uso de células imobilizadas tem sido pouco explorado até o momento. Poucos trabalhos descrevem o comportamento de sistemas com células imobilizadas neste bioprocesso (DOMÍNGUEZ, 1998; CARVALHO et al., 2003, 2004; SANTOS et al., 2004).

É importante salientar que uma das maiores dificuldades na condução de processos biotecnológicos industriais são os baixos valores de produtividade geralmente obtidos.

O uso de sistemas com células imobilizadas tem sido considerado como uma alternativa viável para se aumentar a produtividade de bioprocessos em razão das elevadas densidades celulares obtidas (RAMAKRISHNA; PRAKASHAM, 1999). Além disso, fatores como a possibilidade de desacoplar a dependência da vazão específica de alimentação em relação à velocidade especifica de crescimento celular quando o processo fermentativo é conduzido em modo contínuo (o qual oferece vantagens como redução de tempos mortos e custos de infra-estrutura e geração de produtos com características mais uniformes), a facilidade de reutilização dos 
biocatalisadores, a possibilidade de controle das propriedades reológicas do meio de fermentação, o aumento da estabilidade dos biocatalizadores e a redução de custos operacionais têm sido também considerados como vantagens em relação ao uso de células em suspensão no meio de fermentação (DERVAKOS; WEBB, 1991; PILKINGTON et al., 1998; RAMAKRISHNA; PRAKASHAM, 1999). Outras vantagens da condução de processos com o emprego de células imobilizadas em relação aos processos fermentativos tradicionais, que podem ainda ser citadas, são a possibilidade de operação em sistema contínuo a elevadas vazões de alimentação sem que ocorra lavagem celular (CORCORAN, 1985), e de integração entre fermentação e processo de recuperação de produto (BRODELIUS; VANDAMME, 1987). É interessante lembrar que um fator importante para o sucesso do uso de biocatalizadores imobilizados é a adequada escolha do suporte e da técnica de imobilização.

\section{Imobilização de Células em Gel de Álcool Polivinílico}

O envolvimento de células em matrizes poliméricas é amplamente usado para a imobilização celular. Polímeros naturais e sintéticos têm sido usados, mas ambos apresentam algumas desvantagens. Polímeros naturais como agar, agarose, alginato, kappa-carragena, colágeno e quitosana, apresentam baixa força mecânica e durabilidade, embora não sejam tóxicos aos microrganismos. Por outro lado, polímeros sintéticos como poliacrilamida e poliuretano têm elevada força mecânica e durabilidade, mas freqüentemente são tóxicos aos microrganismos (WU; WISECARVER, 1992; CHANG; TSENG, 1998).

O álcool polivinílico, um promissor polímero sintético, tem sido usado para imobilização celular. É um polímero atrativo para uso como suporte para imobilização, pois é de baixo custo, é produzido em larga escala e é inofensivo a biomateriais como enzimas, células e tecidos (ARIGA et al., 1994).
O PVA é obtido da polimerização do acetato de vinila (FIGURA 4) e subseqüente hidrólise parcial do acetato de polivinila (RODWELL et al., 2003). Após a reação de polimerização, o acetato de polivinila é então submetido a uma reação denominada hidrólise, onde os grupos acetato são substituídos por grupos alcoólicos. Através do controle desta reação o álcool pode ser produzido com níveis de hidrólise entre $70 \%$ e $100 \%$, os quais representam a porcentagem de grupos de acetato convertidos em grupos alcoólicos no polímero. É geralmente classificado em dois grupos, parcialmente hidrolisado e completamente hidrolisado e suas propriedades estão baseadas no seu peso molecular e grau de hidrólise (DeMERLIS; SHONEKER, 2003).

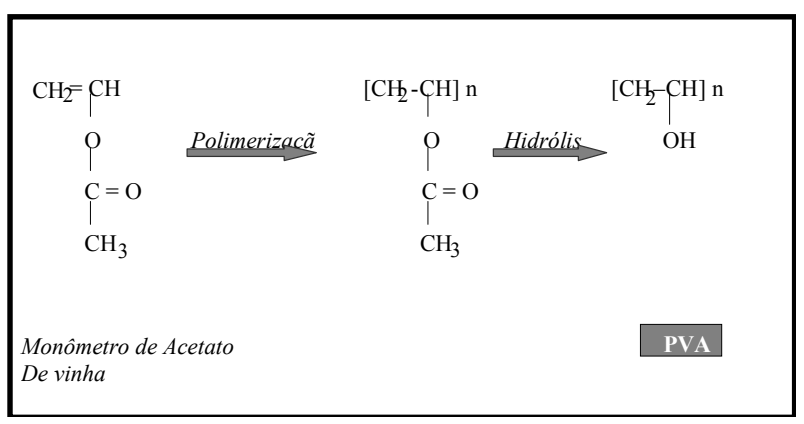

Figura 3 - Representação esquemática da obtenção industrial do álcool polivinílico

Soluções aquosas concentradas de PVA são capazes de gelificação com a formação de uma rede espacial não covalente, sob estocagem prolongada (LOZINSKY; PLIEVA, 1998). É possível também obtenção de gel através do congelamento e subseqüente descongelamento de soluções concentradas do polímero, sendo este denominado de PVA-criogel. É um gel termorreversível que se funde quando aquecido a $70^{\circ} \mathrm{C}$ - $80^{\circ} \mathrm{C}$ e para sua preparação não é necessário o uso de temperaturas muito baixas, pois temperaturas entre $-10^{\circ} \mathrm{C}$ e $-30^{\circ} \mathrm{C}$ são suficientes (LOZINSKY; ZUBOV; TITOVA, 1996).

Dados de literatura apontam aumento do número de áreas onde é proposto o uso de PVA-criogel, como por exemplo, na medicina como suporte liberador de drogas ou como substituto protético de tecido cartilaginoso; na microbiologia para o preparo de meio 
nutricional sólido; na pesca como isca artificial; na indústria de alimentos como envoltório protetor para carnes e peixes, além da aplicação do PVA-criogel para a imobilização de células e exploração de biocatalizadores imobilizados, preparados por uma variedade de processos biotecnológicos (LOZINSKY; PLIEVA, 1998).

Alguns procedimentos têm sido utilizados para o aprisionamento de biomassa microbiana em PVAcriogel. O primeiro envolve o congelamento de uma suspensão de células em solução de PVA em um molde especial e subseqüente sublimação parcial do gelo da amostra congelada, seguido de descongelamento e expansão em um meio líquido apropriado. Este procedimento induz a formação de PVA-criogel contendo células aprisionadas, possuindo uma estrutura anisotrópica heterogênea. $O$ segundo procedimento consiste de vários tratamentos de congelamento e descongelamento de células suspensas em solução de PVA. Tanto a liofilização parcial quanto o tratamento criogênico múltiplo são usados para aumentar a força mecânica do gel obtido, mas eles podem prejudicar o emprego de muitos materiais microbianos devido a danos na célula. A terceira técnica envolve um único ciclo de congelamentodescongelamento, sem liofilização. Neste procedimento as propriedades mecânicas do PVA-criogel com as células aprisionadas são controladas pelas condições da etapa de descongelamento (descongelamento lento resulta PVA-criogel de alta força) segundo Lozinsky, Zubov e Titova (1996).

São encontrados na literatura outros métodos para obtenção de gel de álcool polivinílico com células ou enzimas imobilizadas sem o uso de congelamentodescongelamento, e isto é interessante do ponto de vista econômico, pois menor quantidade de energia é requerida.

O método de luz ultravioleta, descrito por Imai et al. (1986), os quais estudaram a imobilização de amiloglicosidase, invertase e celulase em uma membrana de PVA, obtida por meio de irradiação UV. O método do ácido bórico descrito por
Hashiimoto e Furukawa (1987), onde lodo ativado foi imobilizado em gel de PVA-ácido bórico, obtido por gotejamento de uma mistura de lodo e solução do polímero em uma solução saturada de ácido bórico.

Os métodos de congelamento-descongelamento e de ultravioleta requerem equipamentos específicos para obtenção do gel de PVA, sendo portanto técnicas mas elaboradas, já o método do ácido bórico é uma técnica simples e econômica, no entanto, há dois potenciais problemas que são a aglomeração das esferas de PVA obtidas e a toxicidade da solução de ácido bórico ao microrganismo (CHANG; TSENG, 1998). Para superar estes problemas, Wu e Wisecarner (1992) utilizaram pequena quantidade de alginato de cálcio para prevenir aglomeração das esferas de PVA. Chen e Lin (1994) reduziram o tempo de imersão na solução de ácido bórico de 15$24 \mathrm{~h}$ para 10 min- 2 h através do uso de solução de ortofosfato de sódio para aumentar a força do gel. Porém, estas duas modificações não eliminaram completamente os problemas (CHANG; TSENG, 1998).

Chang e Tseng (1998) desenvolveram um método simples, que não requer equipamentos específicos como câmara de UV ou ultrafreezer e que previne a aglomeração das esferas de PVA e elimina o problema da toxicidade do ácido bórico. Neste método, o ácido bórico é substituído por nitrato de sódio para gelificação do PVA, sendo utilizada pequena quantidade de alginato para prevenir a aglomeração das esferas.

\section{Considerações Finais}

A vasta extensão territorial do Brasil e sua grande biodiversidade microbiana, aliada ao grande número de agroindústrias grande resíduos e subprodutos que podem ser aproveitados para produção de produtos de alto valor agregado, enfatizando a importância da biotecnologia seja no ponto de vista econômico ou ambiental. 
O bagaço de cana-de-açúcar, que é um resíduo rico em carboidratos e produzido em grandes quantidades devido à existência de diversas usinas sucroalcooleiras, sobretudo na região sudeste brasileira, pode ser utilizado para a obtenção de xilitol, uma biomolécula que apresenta potencial de aplicação nas indústrias alimentícias e farmacêuticas. Sendo, portanto, interessante a sua obtenção a partir de materiais de baixo custo através de processos biotecnológicos.

É interessante o uso de técnicas de imobilização celular para a produção de xilitol, visando aumento de produtividade, e um suporte para imobilização microbiana com características adequadas o gel de álcool polivinílico, um material que pode ser explorado na bioprodução de xilitol, podendo abrir desta forma, novos caminhos com relação a sua aplicação em processos microbianos.

\section{Agradecimentos}

Os autores agradecem a Fundação de Amparo a Pesquisa do Estado de São Paulo (FAPESP) e ao Conselho Nacional de Desenvolvimento Científico e Tecnológico $(C N P Q)$.

\section{Referências}

ANVISA. Resolução RDC n ${ }^{\circ}$, de 2 de janeiro de 2001. Aprova o Regulamento Técnico que aprova o uso de Aditivos Edulcorantes, Estabelecendo seus Limites Máximos para os Alimentos. Disponível em: < www.anvisa.gov.br/legis/resol/ 2001/02.rdc.htm>. Acesso em: 29 mar. 2004a.

ANVISA. Resolução no 386 de 5 de agosto de 1999. Aprova o Regulamento técnico sobre aditivos utilizados segundo as boas práticas de fabricação e suas funções, contendo os Procedimentos para Consulta da Tabela e a Tabela de Aditivos Utilizados Segundo as Boas Práticas de Fabricação. Disponível em: <www.anvisa.gov.br/legis/ $\mathrm{resol} / 386$ 99.htm>. Acesso em: 29 mar. 2004b.

ARIGA, O.; ITOH, K.; SANO, Y.; NAGURA, M. Encapsulation of biocatalyst with PVA capsules. Journal of Fermentation and Bioengineering, Osaka, v. 78, n. 1, p. 74-78, 1994.
BÄR, A. Xylitol. In: O'BREEN NABORS L.; GELARDI, R. C. (Ed.). Alternative Sweeteners. New York: Basel, 1986. p.185-216.

BÄR, A. Xylitol. In: O'BREEN NABORS, L., GELARDI, R. C. (Ed.) Alternative sweeteners. New York: Marcel Deckker, 1991.p. 349-379.

BARNETT, J. A. The utilization of sugars by yeasts. Advances in Carbohydrate Chemistry and Biochemistry, New York, v.32, p.125-234, 1976.

BRASIL. Ministério da Agricultura. Disponível em: $<$ www.agricultura.gov.br>. Acesso em 29 mar. 2004.

BRODELIUS, P., VANDAMME, E. J. Immobilized cell systems. In: REHM, H. J., REED, G. (Ed.). Biotechnology: a Comprehensive Treatise. London: J.F. Kennedy, 1987. v.7a, p.405-464.

CARVALHO, W.; SANTOS, J. C.; CANILHA, L.; ALMEIDA E SILVA, J. B.; FELIPE, M. G. A.; MANCILHA, I. M.; SILVA, S. S. A study on xylitol production from sugarcane bagasse hemicellulosic hydrolysate by $\mathrm{Ca}$ alginate entrapped cells in a stirred tank reactor. Process Biochemistry, London, v. 39, p. 2135-2141, 2004.

CARVALHO, W.; SILVA, S. S.; CONVERTI, A.; VITOLO, M.; FELIPE, M. G. A.; ROBERTO, I. C.; SILVA, M. B.; MANÇILHA, I. M. Use of immobilized Candida Yeast cells for xylitol production from sugarcane bagasse hrydrolisate. Applied Biochemistry and Biotechnology, Clifton, v. 98-100, p. 489-496, 2002.

CARVALHO, W.; SILVA, S. S.; SANTOS, J. C.; CONVERTI, A. Xylitol production by Ca-alginate entrapped cells: comparison of different fermentation systems. Enzyme and Microbial Technology, New York, v. 32, p. 553-559, 2003.

CHANG, C. C., TSENG, S. K. Immobilization of Alcaligenes eutrophus using PVA crosslinked with sodium nitrate. Biotechnology Techniques, Kew, v.12, p. 865-868, 1998.

CHEN, K.; LIN, Y. Immobilization of microorganisms with phosphorylated polyvinyl alcohol gel. Enzyme and Microbial Technology, New York, v.16, p. 79-83, 1994.

CORCORAN, J. A. The production and use of immobilized living microbial cells. In: WISEMAN, A. (Ed.). Topics in Enzyme and Fermentation Biotechnology. England: Ellis Horwood Limited, 1985. v.10, p.12-50.

CULBERT, S. J., WANG, Y. M., FRITSCHE, H. A., CARR, D., LANTIN, E. van EYS, J. Oral xylitol in American adults. Nutrition Research, Tarrytown, v. 6, p.913-922, 1986.

DeMERLIS, C. C., SCHONEKER, D. R. Review of the oral toxicity of polyninyl alcohol (PVA). Food and Chemical Toxicology, Oxford, v. 41, p. 319-326, 2003. 
DERVAKOS, G. A.; WEBB, C. On the merits of viable-cell immobilization. Biotechnology Advances, New York, v.9, n.4, p.559-612, 1991.

DOMÍNGUEZ, J. M. Xylitol production by free and immobilized Debaromyces hansenii. Biotechnology Letters, Dordrecht, v.20, n.1, p.53-56, 1998.

DU TOIT, P. J.; OLIVIER, S. P.; VAN BILJON, P. L. Sugar cane bagasse as a possible source of fermentable carbohydrates. 1 . Characterization of bagasse with regard to monosaccharide. Hemicellulose and amino acid composition. Biotechnology and Bioengineering, New York, v.26, p.1071-1078, 1984.

EMODI, A. Xylitol, its properties and food aplications. Food Technology, Chicago, v.32, n.2, p. 28-32, 1978.

FERNÁNDEZ DEGIORGI, C.; PIZARRO, R. A.; SMOLKO, E. E.; LORA, S.; CARENZA, M. Hydrogels for immobilization of bacteria used in the treatment of metalcontaminated wastes. Radiation Physics Chemistry, Oxford, v. 63, n.1, p. 109-113, 2002.

GERBSCH, N.; BUCHHOLZ, R. New processes and actual trends in biotechnology. FEMS Microbiology Reviews, Amsterdam, v. 16, p. 259-269, 1995.

GIULIANO, M.; SCHIRALD, C.; MARESCA, C.; ESPOSITO, V.; DE ROSA, M. Immobilized Proteus mirabilis in poly (vinyl alcohol) cryogels for $\mathrm{L}(-)$-carnitine production. Enzyme and Microbial Technology, New York, v. 32, p. 507-512, 2003.

GOLDSTEIN, I. S. Organic chemicals from biomass. Boca Raton: CRC Press, 1991.

GROBOILLOT, A.; BOADI, D.K.; PONCELET, D.; NEUFELD, R.J. Immobilization of cells for application in the food industry. Critical Reviews in Biotechnology, Boca Raton, v. 14, p. 75-107, 1994.

HASHIMOTO, S.; FURUKAWA, K. Immobilization activated sludge by PVA-boric acid method. Biotechnology and Bioengineering, New York, v. 30, p. 52-59, 1987.

HYVÖNEN, L.; KOIVISTOINEN, P.; VOIROL, F. Food Technological evaluation of xylitol. Advances in Food Research, San Diego, v.28, p.373-403, 1982.

IMAI, K., SHIOMI, TOMOO, UCHIDA, K., MIYA, M. Immobilization of enzyme into poly(vinyl alcohol) membrane. Biotechnology and Bioengineering, New York, v. 28, p. 1721-1726, 1986.

JEFFRIES, T. W. Utilization of xylose by bacteria, yeasts and fungi. Advances in Biochemical Engineering, New York, v.27, p.1-32, 1983.
KADAM, K. L.; FORREST, L. H.; JACOBSON, W. A. Rice straw as a lignocellulosic resource: collection,processing, transportation, and environmental aspects. Biomass and Bioenergy, Oxford, v. 18, p. 369-389, 2000.

KANDELMAM, D. Sugar, alternative sweeteners and meal frequency in relation to caries prevention: new perspectives. British Journal of Nutrition, Cambridge, v. 77, p. S121-S128, 1997.

KAREL, S.F.; LIBICKI, S.B.; ROBERTSON, C.R. The immobilization of whole cells: Engineering principles. Chemical Engineering Science, New York, v. 40, p. 13211354, 1985.

KRISHNA, S. H.; REDDY, T. J.; CHOWDARY, G. V. Simultaneous saccharification and fermentation of lignocellulosic wastes to ethanol using a thermotolerant yeast. Bioreseourch Technology, Essex, v. 77, p. 193-196, 2001.

KUHAD, R. C.; SINGH, A. Lignocellulose Biotechnology: Current and Future Prospects. Critical Reviews in Biotechnology, Boca Raton, v.13, p. 151-173, 1994.

LACÔRTE, M. C. G.; BURGE, R.; LACÔRTE, A. J. F. bagaço de cana hidrolisado já é utilizado em larga escala em confinamento. STAB, Açúcar, Álcool e Subprodutos, Piracicaba, v. 5, n. 2, p. 43-52, 1986.

LATIF, F.; RAJOCA, M. I. Production of ethanol and xylitol from corncobs by yeasts. Bioresearch Technology, Essex, v. 77, p. 57-63, 2001.

LOZINSKY, V. L.; PLIEVA, F. M. Poly (vinyl alcohol) cryogels employed as matrices for cell immobilization. 3 . Overview of recent research and developments. Enzyme and Microbial Technology, New York, v. 23, p. 227-242, 1998.

LOZINSKY, V. L.; ZUBOV, A. L; TITOVA, E. F. Swelling behavior of poly (vinyl alcohol) cryogels employed as matrices for cell immobilization. Enzyme and Microbial Technology, New York, v. 18, p. 561-569, 1996.

MÄKINEN, K. K. Can the pentitol-hexitol theory explain the clinical observations made with xylitol? Medical Hypothesis, Penrith, v. 54 p. 603-613, 2000.

MÄKINEN, K. K. Xylitol: The sugar that prevents tooth decay. The Futurist, Washington, v.10, n.3, p.135-139, 1976.

MANZ, U.; VANNINEN, E.; VOIROL, F. Xylitol - its properties and use as a sugar substitute in foods. In: FOOD R. A. Symposium Sugar and Sugar Replacements. London, 1973.

MATTILA, P. T.; SVANBERG, M. J.; JAMSA, T.; KNUUTTILA, M. L. E. Improved bone biomechanical properties in xylitol-fed aged rats. Metabolism Clinical and Experimental, Oulu, v. 51, n.1, p.92-96, 2002. 
MELAJA, A. J.; HÄMÄLÄINEN, L. Process for making xylitol. US Patent 4.008.285, 15 fev. 1977.

MEYRIAL, V.; DELGENES, J. P.; MOLETTA, R.; NAVARRO, J. M. Xylitol production from D-xylose by Candida guilliermondii: Fermentation behaviour. Biotechnology Letters, Dordrecht, v. 13, p. 113-118, 1991.

MOLINA JUNIOR, W. F.; RIPOLI, T. C.; GERALDI, R. N.; AMARAL, J. R. Aspectos econômicos e operacionais do enfardamento de resíduo de colheita de cana-de-açúcar para aproveitamento energético. STAB-Açúcar, Álcool e Subprodutos, Piracicaba, v. 13, n. 5, p. 28-31, 1995.

NOLLEAU, V.; PREZIOSI-BELLOY,L;;NAVARRO, J.M. The reduction of xylose to xylitol by Candida guilliermondii and Candida parapsilosis: Incidence of oxygen and $\mathrm{pH}$. Biotechnology Letters, Dordrecht, v.117, p.417-422, 1995.

OJAMO, H.; YLINEN, L.; LINKO, M. Process for the preparation of xylitol from xylose by cultivating Candida guilliermondii. US Patent WO 88/05467, 1988.

PANDEY, A.; SOCOOL, C. R.; NIGAM, P.; SOCOOL, V. Biotechnological potential of agro-industrial residues. I: sugarcane bagasse. Bioresearch Technology, Essex, v. 74, p. 69-80, 2000.

PARK, J.K.; CHANG, H.N. Microencapsulating of microbial cells. Biotechnology Advances, New York, v. 18, p. 303-319, 2000.

PASCO, N.; BARONIAN, K.; JEFFRIES, C.; WEBBER, J.; HAY, J. Micredoxâ - development of a ferricyanidemediated rapid biochemical oxygen demand method using an immobilised Proteus vulgaris biocomponent. Biosensors \& Bioelectronics, Essex, 2004 (in press).

PEPPER, T.; OLINGER, P. M. Xylitol in sugar-free confections. Food Technology, Chicago, v. 42, p. 98-106, 1988.

PILKINGTON, P. H.; MARGARITIS, A; MENSOUR, N. A; RUSSELL, I. Fundamentals of immobilized yeast cells for continuous beer fermentation: a review. Journal of the Institute of Brewing, London, v.104, p.19-31, 1998.

RAMAKRISHNA, S. V.; PRAKASHAM, R. S. Microbial fermentations with immobilized cells. Current Science, Columbus, v. 77, n.1, p.87-100, 1999.

RODWELL, D. E., KELLY, C. M., DeMERLIS, C. C., SHONEKER, D. R., BORZELLECA, J. F. Effects of polyvinyl alcohol administered in the diet to rats on fertility, early embryonic development, growth and development. Food and Chemical Toxicology, Oxford, v 41, p. 729-737, 2003.

ROSEIRO, J. C.; PEITO, M. A.; GÍRIO, F. M.; AMARALCOLLAÇO, M. T. The effects of the oxygen transfer coefficient and substrate concentration on the xylose fermentation by Debaromyces hansenii. Archives of Microbiology, Berlin, v. 156, p. 484-490, 1991.
SILVA, S. S.; CARVALHO, W. Xylitol production by Caalginate entrapped cells: comparison of different fermentation systems. Enzyme and Microbiology Technology, New York, v. 1, p. 1, 2002.

SANTOS, J. C.; CONVERTI, A.; CARVALHO, W.; MUSSATTO, S. I.; SILVA, S. S. Influence of aeration rate and carrier concentration on xylitol production from sugarcane bagasse hydrolysate in immobilized-cell fluidized bed reactor. Process Biochemistry, London, 2004 (in press).

SILVA, S. S.; CARVALHO, W.; CONVERTI, A.; VITOLO, M. Metabolic behavior of immobilized Candida guilliermondii cells during batch xylitol production from sugarcane bagasse acid hydrolizate. Biotechnology and Bioengineering, New York, v. 79, n. 2, p. 165-169, 2002.

SILVA, S. S.; CONVERTI, A.; ZILLI, M.; SENE, L.; FELIPE, M. G. A. Metabolic study of the adaptation of the yeast Candida guilliermondii to sugarcane bagasse hydrolysate. Applied Biochemistry and Biotechnology, Clifton, v. 57, p. 738-743, 2001.

SILVA, S. S.; MARTINEZ, E. A.; FELIPE, M. G. A. Effect of oxygen volumetric transfer coefficient on xylitol production from sugarcane hydrolysate. Applied Biochemistry and Biotechnology, Clifton, v. 84-86, p. 633$641,2000$.

SILVA, S. S.; RIBEIRO, J. D.; FELIPE, M. G. A.; VITOLO, M. Maximizing the xylitol production from sugarcane bagasse hydrolisate by controlling the aeration rate. Applied Biochemistry and Biotechnology, Clifton, v. 63/ 64, p. 557-563, 1997.

UHARI M, T.; APIAINEN, T.; KONTIOKARI, T. Xylitol in preventing acute otitis media. Vaccine, Kidlinton, v. 19, suppl.1, p. S144-147, 2000.

UHARI M, T.; KONTIOKARI, T.; NIEMELA, M. A novel use of xylitol sugar in preventing acute otitis media. Pediatrics, New York, v. 102, n.4, p. 878-884, 1998.

WINKELHAUSEN, E.; KUSMANOVA, S. Microbial Conversion of D-Xylose to Xylitol. Journal of Fermentation and Bioengineering, Osaka, v. 86, n. 1, p. 1-14, 1998.

WU, K. A.; WISECARVER, K.D. Cell immobilization using PVA crosslinked with boric acid. Biotechnology and Bioengineering, New York, v. 39, p. 447-449, 1992.

YLIKAHRI, R. Metabolic and nutritional aspects of xylitol. Advances in Food Research, San Diego, v.25, p. 159-180, 1979. 